\title{
Erectile dysfunction and phosphodiesterase type 5 inhibitor use: associations with sexual activities, function and satisfaction in a population sample of older men
} DOI:

10.1038/ijir.2015.4

\section{Document Version \\ Accepted author manuscript}

Link to publication record in Manchester Research Explorer

Citation for published version (APA):

Lee, DM., Nazroo, J., \& Pendleton, N. (2015). Erectile dysfunction and phosphodiesterase type 5 inhibitor use: associations with sexual activities, function and satisfaction in a population sample of older men. International Journal of Impotence Research, 27, 146-151. [IJIR-09-2014-076R]. https://doi.org/10.1038/ijir.2015.4

\section{Published in:}

International Journal of Impotence Research

\section{Citing this paper}

Please note that where the full-text provided on Manchester Research Explorer is the Author Accepted Manuscript or Proof version this may differ from the final Published version. If citing, it is advised that you check and use the publisher's definitive version.

\section{General rights}

Copyright and moral rights for the publications made accessible in the Research Explorer are retained by the authors and/or other copyright owners and it is a condition of accessing publications that users recognise and abide by the legal requirements associated with these rights.

\section{Takedown policy}

If you believe that this document breaches copyright please refer to the University of Manchester's Takedown Procedures [http://man.ac.uk/04Y6Bo] or contact uml.scholarlycommunications@manchester.ac.uk providing relevant details, so we can investigate your claim.

\section{OPEN ACCESS}




\section{Erectile dysfunction and phosphodiesterase type 5 inhibitor use: associations with sexual activities, function and satisfaction in a population sample of older men}

David M. Lee PhD, ${ }^{1}$ James Nazroo PhD, ${ }^{1}$ Neil Pendleton MD, ${ }^{2}$

${ }^{1}$ Cathie Marsh Institute for Social Research, Humanities Bridgeford Street, Oxford Road, The University of Manchester, Manchester M13 9PL, United Kingdom

${ }^{2}$ Institute of Brain, Behaviour and Mental Health, The University of Manchester, Clinical

Sciences Building, Stott Lane, Salford, M6 8HD, United Kingdom

Correspondence to: david.m.lee@ manchester.ac.uk

Telephone: +44(0)161306 6952

Fax: +44(0)1612750275

Running Title: Erectile dysfunction and sexual health in older men

Funding Sources: DML is a Research into Ageing Fellow. This study was funded by the National Institute on Aging [grants 2RO1AG7644-01A1 and 2RO1AG017644] and a consortium of UK Government departments coordinated by the Office for National Statistics. JN and NP were supported by the fRaill project [grant MRC G1001375/1] as part of the cross-research council Life Long Health and Wellbeing Programme. 


\section{ABSTRACT}

The objective of this study was to examine the association between sexual activities, problems and satisfaction, and erectile dysfunction (ED) and phosphodiesterase type 5 inhibitor (PDE5i) use. A nationally-representative sample of men $(n=2612)$ aged 51 to 87 years from the English Longitudinal Study of Ageing completed an in-depth Sexual Relationships and Activities Questionnaire. Associations between ED and/or PDE5i use and sexual outcomes were explored using logistic regression models adjusted for age, health and lifestyle factors. PDE5i use in the preceding 3 months was reported by a total of 191 (7\%) men, while 542 (21\%) reported ED but no PDE5i use (untreated ED). Compared to men without ED, PDE5i users were more likely to be sexually active and report more frequent sexual intercourse. Men with untreated ED reported the lowest frequency of sexual activities. Compared to men without ED, both PDE5i users and those with untreated ED were more likely to report being concerned about their level of sexual desire, frequency of sexual activities, erectile function, waking erections and orgasmic experience. PDE5i users were also more concerned about and dissatisfied with their overall sex life than men without ED. This population-based study shows that while PDE5i use is associated with improved sexual functioning, this is not equally reflected in decreased levels of concern and dissatisfaction with their overall sexual health. Clinicians should be aware of this disparity between functional gains and continuing sexual concerns and dissatisfaction and, where appropriate, offer psychosexual counselling as an adjunct to PDE5i medication.

Keywords: phosphodiesterase type 5 inhibitor; erectile dysfunction; sexual function; sexual satisfaction; population-based; ELSA 


\section{INTRODUCTION}

The widespread use of phosphodiesterase type 5 inhibitors (PDE5i), such as sildenafil

(Viagra), tadalafil (Cialis) and vardenafil (Levitra), has dramatically changed the treatment of erectile dysfunction (ED) in men. Although an abundance of studies have demonstrated the efficacy of sildenafil, tadalafil and vardenafil in improving erectile function, ${ }^{1}$ they have mainly focussed on clinical trials, patient groups seeking treatment, or unrepresentative samples of community-dwelling men. The effectiveness of this class of drugs among men in a population-based setting, both in terms of functional gains and improved sexual wellbeing, remains less clear. This lack of knowledge, together with an ageing population, ${ }^{2}$ rising levels of obesity, ${ }^{3}$ and an increasing prevalence of chronic diseases associated with ED such as type 2 diabetes, ${ }^{4}$ means that data are needed describing the impact and effectiveness of PDE5i use on sexual functioning, satisfaction and wellbeing in a nationally-representative sample of older men.

The English Longitudinal Study of Ageing (ELSA), a representative survey of a cohort aged 50 to >90 years, has gathered detailed longitudinal data since 2002 on changes in health, economic and social circumstances in later life. ${ }^{5}$ The latest wave of ELSA included a comprehensive Sexual Relationships and Activities Questionnaire (SRA-Q) (with versions specific for men and women) capturing information on sexual behaviours and activities, sexual attitudes, sexual function, sexual health concerns and partnership satisfaction. This paper outlines the associations between ED status, and sexual activities and satisfaction in a nationally-representative sample of older men. We examined whether men who reported PDE5i use were more sexually active and more sexually satisfied than those with untreated ED, and whether PDE5i users had equivalent levels of sexual function and satisfaction as men without ED. 


\section{METHODS}

Sample

The data are from wave 6 (2012/2013) of ELSA, a nationally representative panel survey of community-dwelling men and women aged 50 years and older in England. Full details on the study design and methods have been described previously. ${ }^{5}$ Data collection consisted of a face-to-face interview and self-completion questionnaires. A total of 10601 individuals participated in wave 6, with 7079 (67\%) completing and returning the paper-based Sexual Relationships and Activities Questionnaire (SRA-Q). This analysis included only men with complete data on erectile function and PDE5i usage, and was additionally restricted to the age range covered by the PDE5i users (51-87 years), leaving a total sample of 2612. ELSA wave 6 received ethical approval from the NRES Committee South Central - Berkshire, and all participants were provided with a letter and leaflet to allow them to give informed consent.

\section{Sexual relationships and activities}

The ELSA SRA-Q includes questions on attitudes to sex, sexual activities and behaviours, problems and concerns, and details about current sexual partnerships. Items included in the SRA-Q were taken from validated instruments, ${ }^{6-8}$ with minor modification to ensure gender specificity, and chosen to maximize harmonization with both the US National Social Life, Health, and Aging Study (NSHAP) ${ }^{9}$ and the third UK National Survey of Sexual Attitudes and Lifestyles (Natsal-3). ${ }^{10}$ Face validity of the ELSA SRA-Q was assessed by cognitive interviews among a sample $(n=45)$ of the ELSA pilot/dress rehearsal panel. The cognitive testing was carried out by NatCen Social Research (NatCen) and interviews were conducted by specialist cognitive interviewers. The full range of sexuality measures assessed in the SRA-Q, and cross-sectional associations with demographic, lifestyle and health factors have been described previously. ${ }^{11}$ Table 1 summarizes the items from the SRA-Q presented in this 
analysis. Men were also asked if they had used any oral medications (Viagra, Cialis, Levitra) to enhance their erections over the past three months. Those answering yes were additionally asked to rate the effect of these medications on their sex life (5-point Likert scale: response set 'very positive', 'positive', 'neither positive nor negative', 'negative', 'very negative'). The SRA-Q was completed in private and the questionnaire sealed in an envelope upon completion. The male and female versions of the SRA-Q are freely available from the web site of the Institute for Fiscal Studies (http://www.elsa-project.ac.uk/).

\section{Other assessments}

Participants were asked about their current living arrangements, general health and lifestyle factors during the face-to-face interview. Specifically, they were asked whether a doctor had ever told them they had any of several common conditions, including hypertension, arthritis, cardiovascular diseases, diabetes and asthma. Self-rated health was ranked on a five-point scale (excellent, very good, good, poor or fair), smoking status was recorded as current or non-smoker, and typical frequency of alcohol consumption over the past year as never or rarely (never - once or twice), regularly (once every 2 months - twice a week) or frequently (3 days a week - almost every day). Depressive symptoms were assessed using the eightitem version of the Centre for Epidemiologic Studies Depression (CES-D) scale, with a score of four or more indicative of risk for depression. ${ }^{12}$

\section{Statistical analysis}

All analyses were conducted using STATA SE v13.1 (StataCorp, College Station, TX).

Weights were used to correct for sampling probabilities and differential non-response, including to the SRA-Q, and to calibrate back to the 2011 Census population distributions for sex and age. Specifically, these weights accounted for (i) the differential probability of being 
included in the wave 6 sample and (ii) for non-response to the SRA-Q instrument (full details available from http://www.ifs.org.uk/ELSA). Multiple logistic regression was used to examine the association of PDE5 inhibitor use with sexual activities, function and problems among men, with results expressed as odds ratios (OR) and 95\% confidence intervals (CI).

\section{RESULTS}

Characteristics of the 2612 men included in the analysis are shown in Table 2. Those reporting no $\mathrm{ED}(\mathrm{n}=1879,71.9 \%)$ were the youngest group with a mean $(95 \% \mathrm{CI})$ age of 61.8 (61.3-62.3) years compared to the PDE5i users $(n=191,7.3 \%)$ with a mean age of $64.6(63.0-$ 66.1). Those with ED and not using PDE5i medication, i.e. untreated ED ( $n=542,20.8 \%)$, were the oldest group at 74.4 (73.5-75.3) years. Among PDE5i users, 18 (9\%) men still reported having ED, while $47(25 \%)$ rated the impact of the PDE5i medications on their sex lives as 'very positive' and $105(57 \%)$ as 'positive'. Overall, the number (percentage) of men reporting they were "never able to get or keep an erection which would be good enough for sexual activity" (irrespective of reported PDE5i usage) was 19 (3.1\%) among those aged 5059 years, $143(13.2 \%)$ among those aged 60-69 years, 259 (36.1\%) among those aged 70-79 years, and $139(68.1 \%)$ among those aged 80 years or older. Compared to men without ED, those with untreated ED had poorer self-rated health, were more likely to have all of the listed chronic conditions apart from asthma, left education at a younger age and were less likely to drink alcohol as frequently. Lifestyle and health differences between men without ED and those who reported PDE5i use were less marked, although the PDE5i users were more likely to report high blood pressure and diabetes.

Table 3 summarises the associations between ED status and/or PDEi5 use and sexual activities and function. Multiple logistic regression models were adjusted for demographic and lifestyle factors that differed between the PDE5i use/ED status groups, i.e., age, self-rated 
health, frequency of alcohol consumption and age left education. PDE5i users were more likely to report any sexual activity in the last year $(\mathrm{OR}=6.5,95 \% \mathrm{CI}=2.2-19)$, more frequent sexual intercourse $(\mathrm{OR}=2.9,95 \% \mathrm{CI}=2.0-4.3)$ and more frequent kissing or petting $(\mathrm{OR}=2.6$, 95\% $\mathrm{CI}=1.8-3.9)$, as compared to men without ED. In contrast, compared to the no ED group, men with untreated ED were less likely to be sexually active $(\mathrm{OR}=0.18,95 \% \mathrm{CI}=0.13$ 0.24) and reported lower frequencies of all sexual activities apart from masturbation. Both PDE5i users and those with untreated ED were more likely to report difficulties achieving orgasm and greater declines in erectile ability compared with a year ago (Table 3).

When compared to men without ED, a higher proportion of those either using PDE5i or with untreated ED, reported being worried or concerned about their sexual activities and function (Table 4). The likelihood of reporting concerns about erectile ability was highest among PDE5i users $(\mathrm{OR}=6.9,95 \% \mathrm{CI}=4.6-10$; compared to the no ED group), while among those with untreated ED it was concerns about their orgasmic experience $(\mathrm{OR}=5.1,95 \%$ $\mathrm{CI}=3.1-8.5$; compared to the no ED group). Among men with untreated ED, $43 \%$ reported they did not share the same sexual likes and dislikes with their partner $(\mathrm{OR}=3.1,95 \% \mathrm{CI}=1.6-$ 6.0; compared to the no ED group). Additionally adjusting these models for frequency of sexual activities (intercourse, petting or masturbation frequency) did not markedly change the magnitude or significance of these associations among either PDE5i users or those with untreated ED (data not shown).

When the analyses examining the associations between ED status and/or PDEi5 use, and sexual concerns and satisfaction were repeated excluding those PDE5i users who did not rate the effect of these medications on their sex life as 'very positive' or 'positive' $(n=35)$, the associations between PDE5i use and concerns about sexual activities and function were broadly unchanged compared to those observed among all PDE5i users (data not shown). 


\section{DISCUSSION}

In this nationally-representative sample of older men in England, PDE5i users reported higher levels of sexual activity and function than men without ED, but were also more likely to be concerned and/or dissatisfied with their sexual lives. In contrast, men with untreated ED reported the lowest levels of sexual activity and function, although they were no more likely than PDE5i users to report sexual concerns and dissatisfaction.

Notwithstanding variations in definition, the prevalence of ED has been reported to be 1$10 \%$ in men under 40 years of age, $2-9 \%$ in men aged $40-49,20-40 \%$ in men aged $60-69$ and $50-100 \%$ among those aged over $70 .{ }^{13}$ The prevalence of ED (irrespective of reported PDE5i use) among the equivalent age categories in our study was somewhat lower, probably reflecting the stringent definition we used to categorise ED, i.e., limited to those men answering 'never able' to the question 'Are you able to get or keep an erection which would be good enough for sexual activity?' The psychological and social effects of ED on men have been documented in various studies with respect to reduced self-esteem, negative impacts on relationship, threats to feelings of masculinity and impacts on quality of life. ${ }^{14-16}$ Several observational studies have also revealed robust associations between ED and diabetes, cardiovascular disease and depression. ${ }^{17-21}$ Our data correspond with these findings, with men reporting untreated ED having the highest prevalence of high blood pressure, CVD, diabetes and depression. However, the men with untreated ED were significantly older than those without ED, although the associations between untreated ED and these chronic conditions remained significant in age-adjusted logistic regression models (data not shown). With respect to health characteristics, we found that PDE5i users did not differ from men without ED apart from a higher prevalence of high blood pressure and diabetes. This is in agreement with epidemiological findings that, aside from age, type 2 diabetes is the most common risk factor for ED, with ED developing in 50-75\% of diabetics. ${ }^{22}$ 
Oral PDE5i drugs are now regarded as the first-line medical treatment option for ED. The most commonly prescribed PDE5i are sildenafil, tadalafil and vardenafil, with all three having excellent safety profiles and differing mainly in their duration of action. The efficacy of these drugs has been reported to be $>65 \%$ with respect to achieving satisfactory erectile function with tolerable side effects (refs). This is in broad agreement with our observation that $80 \%$ of PDE5i users in ELSA reported the effect of these medications on their sex lives as very positive or positive. We observed that PDE5i users were the most sexually active group in terms of partnered sexual activities, but they also reported greater difficulty in achieving orgasm and greater declines over the past year in erectile abilities and frequency of waking erections, as compared to men without ED. This 'divergence' between improvements in sexual health (at least in terms of frequency of sexual activities) and continuing sexual problems among PDE5i users may reflect the driver of their concern, i.e., that they have higher expectations regarding their level of sexual activity.

Ongoing difficulties achieving orgasm may, in part, reflect the higher prevalence of both high blood pressure and diabetes among the PDE5i group compared to those without ED. Previous studies have shown that treated hypertensive men have a higher incidence of both erectile and ejaculatory dysfunction than untreated men, ${ }^{23}$ while autonomic neuropathy secondary to diabetes has been associated with both anorgasmia and anejaculation. ${ }^{24}$ Greater declines in both erectile ability and the frequency of waking erections over the preceding year among PDE5i users as compared to men without ED is perhaps unsurprising, presumably reflecting the former groups' recognition of decreasing function over time and willingness to try a pharmacological intervention.

Although the majority of PDE5i users in ELSA reported the effect of these medications on their sex lives as positive, when compared to men without ED they consistently reported higher levels of concern and dissatisfaction with various aspects of their sexual activity, 
function and relationships. Few comparable data on community-dwelling men are available, but a study among Australian men recruited over the internet via men's health web sites found that treatment of ED with PDE5i medications did not alleviate deficits in assessments of self-esteem, masculinity, quality of life, sexual satisfaction and relationship satisfaction. ${ }^{25}$ There is an increasing recognition that the most common type of ED seen clinically is of a 'mixed' aetiology, i.e., representing a combination of organic and psychogenic causes. ${ }^{26}$ Our population-data adds to the evidence base that PDE5i use does not simply translate to a uniformly better sex life, supporting the view that ED arises from a mixture of physiological, psychological and social causes. However, primary care physicians typically neglect this complexity when treating many cases of ED. ${ }^{26}$ Time constraints on general practitioners consultation time and an unwillingness among primary care health professionals to discuss sexuality and sexual health with older individuals ${ }^{27,28}$ only compounds this situation, resulting in suboptimal treatment and follow-up for many men with ED. The PDE5i group of drugs are undoubtedly a success story with respect to reviving erectile function in a majority of ED cases with an underlying vasculogenic aetiology. However, opportunities are clearly being missed to improve treatment outcomes and the challenge now is to join up intervention regimes so as to not ignore compounding psychogenic factors and interpersonal contexts. Managing expectations in light of the ongoing hyperbole surrounding Viagra remains an important issue and patients should be provided with unambiguous information that PDE5i drugs do not directly enhance virility or increase sexual desire. Physicians should also be open to discussing with male patients the potential side effects on erectile function of commonly prescribed medications for chronic conditions such as hypertension and type 2 diabetes. Although not assessed in our study, the lack of involvement of partners in the consultation process for men seeking treatment for ED remains the norm. ${ }^{29}$ There is, however, good evidence that ED interventions that combine PDE5i medications with sex 
therapy treatments in the context of the couple are more effective than pharmacological treatments alone. $^{30}$

\section{Strengths and limitations}

The major strengths of ELSA are its large, nationally representative community-based sample covering midlife to the oldest-old, not recruited explicitly to answer questions on their sexual health. Although limitations of the study have been described previously, ${ }^{5}$ certain factors need to be highlighted here. ELSA did not oversample ethnic or sexual minorities and the results presented here may not be generalisable to these groups. In common with similar studies our data were self-reported and, although the interview methods have accepted validity ${ }^{31}$ we cannot exclude reporting bias. Those ELSA participants who did not complete the SRA-Q may not have done so due to pre-existing sexual problems and/or feeling that they were 'retired' from sex. The non-response weights will have partly dealt with this, with weighting for non-response to the SRA-Q instrument directly accounting for the variation in response according to demographic and health characteristics. The cross-sectional data preclude any examination of the temporal nature of associations and we cannot distinguish to what degree age-associated changes in sexual activities and function reflect ageing related or age cohort effects. Finally, we did not obtain information on either the severity of ED or the duration of erectile problems prior to PDE5i treatment, and how these factors may have biased our assessments of sexual concerns and dissatisfaction.

\section{CONCLUSION}

Physicians need to take a fresh look at the overall efficacy of PDE5i medications for the management of erectile dysfunction among older men, recognising that restoring erectile adequacy pharmacologically is not a panacea for all men with ED. Our population-based 
data show that gains relating to sexual activity and function are not mirrored by lower levels of concern and dissatisfaction with sexual health and relationships. A more holistic approach to managing ED should include a well-informed patient with realistic expectations, engagement and support from his partner, and an improved appraisal of any psychological and/or relationship issues that may exacerbate sexual concerns and dissatisfaction. It would also be beneficial if the manufacturers of this group of medications provided more comprehensive information as part of a more rounded treatment and management plan, covering issues beyond basic usage and potential side effects. Additional materials (print and/or multimedia) aimed at both clinicians and end-users should highlight the importance of relational and psychosocial factors as part of a multidisciplinary approach to treatment. The efficacy of PDE5i medications in relation to functional gains is not in doubt, but our data suggest that current approaches to ED treatment are missing important opportunities to improve the broader sexual health and well-being of older men and their partners.

\section{CONFLICT OF INTEREST}

The authors declare no conflict of interest.

\section{ACKOWLEDGEMENTS}

We thank the study participants. DML is a Research into Ageing Fellow. This study was funded by the National Institute on Aging [grants 2RO1AG7644-01A1 and 2RO1AG017644] and a consortium of UK Government departments coordinated by the Office for National Statistics. JN and NP were supported by the fRaill project [grant MRC G1001375/1] as part of the cross-research council Life Long Health and Wellbeing Programme. 


\section{REFERENCES}

1. Yuan J, Zhang R, Yang Z, Lee J, Liu Y, Tian J et al. Comparative effectiveness and safety of oral phosphodiesterase type 5 inhibitors for erectile dysfunction: a systematic review and network meta-analysis. European urology 2013; 63(5): 902-912.

2. ONS. Office for National Statistics. http://www.ons.gov.uk/ons/rel/npp/nationalpopulation-projections/2010-based-projections/index.html, 2011. Accessed 5th March 2014.

3. Howel D. Trends in the prevalence of obesity and overweight in English adults by age and birth cohort, 1991-2006. Public health nutrition 2011; 14(1): 27-33.

4. Federation ID. Diabetes atlas, fifth edition. www.diabetesatlas.org, 2011. Accessed 12th June 2014.

5. Steptoe A, Breeze E, Banks J, Nazroo J. Cohort Profile: the English Longitudinal Study of Ageing. International journal of epidemiology 2013; 42(6): 1640-1648.

6. Mitchell KR, Ploubidis GB, Datta J, Wellings K. The Natsal-SF: a validated measure of sexual function for use in community surveys. European journal of epidemiology 2012; 27(6): 409418.

7. O'Connor DB, Corona G, Forti G, Tajar A, Lee DM, Finn JD et al. Assessment of sexual health in aging men in Europe: development and validation of the European Male Ageing Study sexual function questionnaire. The journal of sexual medicine 2008; 5(6): 1374-1385.

8. Waite $\amalg$, Laumann EO, Das A, Schumm LP. Sexuality: measures of partnerships, practices, attitudes, and problems in the National Social Life, Health, and Aging Study. The journals of gerontology Series B, Psychological sciences and social sciences 2009; 64 Suppl 1: i56-66.

9. Suzman R. The National Social Life, Health, and Aging Project: an introduction. The journals of gerontology Series B, Psychological sciences and social sciences 2009; 64 Suppl 1: i5-11.

10. Mercer $\mathrm{CH}$, Wellings $\mathrm{K}$, Johnson AM. What's new about Natsal-3? Sexually transmitted infections 2013.

11. Lee DM, Nazroo J, O'Connor DB, Blake M, Pendleton N. Sexual Health and Wellbeing Among Older Men and Women in England: Findings from the English Longitudinal Study of Ageing. Archives of sexual behavior 2015; In Press.

12. Steffick DE. Documentation of affective functioning measures in the health and retirement study. Ann Arbor, 2000.

13. Shamloul R, Ghanem H. Erectile dysfunction. Lancet 2013; 381(9861): 153-165.

14. Althof SE. Quality of life and erectile dysfunction. Urology 2002; 59(6): 803-810. 
15. Latini DM, Penson DF, Colwell HH, Lubeck DP, Mehta SS, Henning JM et al. Psychological impact of erectile dysfunction: validation of a new health related quality of life measure for patients with erectile dysfunction. The Journal of urology 2002; 168(5): 2086-2091.

16. Latini DM, Penson DF, Lubeck DP, Wallace KL, Henning JM, Lue TF. Longitudinal differences in disease specific quality of life in men with erectile dysfunction: results from the Exploratory Comprehensive Evaluation of Erectile Dysfunction study. The Journal of urology 2003; 169(4): 1437-1442.

17. Clark NG, Fox KM, Grandy S, Group SS. Symptoms of diabetes and their association with the risk and presence of diabetes: findings from the Study to Help Improve Early evaluation and management of risk factors Leading to Diabetes (SHIELD). Diabetes care 2007; 30(11): 2868-2873.

18. Inman BA, Sauver JL, Jacobson DJ, McGree ME, Nehra A, Lieber MM et al. A populationbased, longitudinal study of erectile dysfunction and future coronary artery disease. Mayo Clinic proceedings 2009; 84(2): 108-113.

19. Ponholzer A, Gutjahr G, Temml C, Madersbacher S. Is erectile dysfunction a predictor of cardiovascular events or stroke? A prospective study using a validated questionnaire. International journal of impotence research 2010; 22(1): 25-29.

20. Quek KF, Sallam AA, $\mathrm{Ng} \mathrm{CH}$, Chua CB. Prevalence of sexual problems and its association with social, psychological and physical factors among men in a Malaysian population: a cross-sectional study. The journal of sexual medicine 2008; 5(1): 70-76.

21. Thompson IM, Tangen CM, Goodman PJ, Probstfield JL, Moinpour CM, Coltman CA. Erectile dysfunction and subsequent cardiovascular disease. JAMA : the journal of the American Medical Association 2005; 294(23): 2996-3002.

22. Lewis RW, Fugl-Meyer KS, Corona G, Hayes RD, Laumann EO, Moreira ED, Jr. et al. Definitions/epidemiology/risk factors for sexual dysfunction. The journal of sexual medicine 2010; 7(4 Pt 2): 1598-1607.

23. Riley AJ, Steiner JA, Cooper R, McPherson CK. The Prevalence of Sexual Dysfunction in Male and Female Hypertensive Patients. Sexual and Marital Therapy 1987; 2(2): 131-138.

24. McMahon CG, Abdo C, Incrocci L, Perelman M, Rowland D, Waldinger M et al. Disorders of orgasm and ejaculation in men. The journal of sexual medicine 2004; 1(1): 58-65.

25. Matic $\mathrm{H}, \mathrm{McCabe}$ MP. The impact of the use of PDE5 inhibitors for erectile dysfunction on the lives of Australian men. International journal of impotence research 2007; 19(4): 418423.

26. Levine SB. Erectile dysfunction: why drug therapy isn't always enough. Cleveland Clinic journal of medicine 2003; 70(3): 241-246.

27. Gott $M$, Hinchliff $S$. Barriers to seeking treatment for sexual problems in primary care: a qualitative study with older people. Family practice 2003; 20(6): 690-695. 
28. Gott M, Hinchliff $S$, Galena E. General practitioner attitudes to discussing sexual health issues with older people. Social science \& medicine 2004; 58(11): 2093-2103.

29. Barnett ZL, Robleda-Gomez S, Pachana NA. Viagra: the little blue pill with big repercussions. Aging \& mental health 2012; 16(1): 84-88.

30. Aubin S, Heiman JR, Berger RE, Murallo AV, Yung-Wen L. Comparing Sildenafil alone vs. Sildenafil plus brief couple sex therapy on erectile dysfunction and couples' sexual and marital quality of life: a pilot study. Journal of sex \& marital therapy 2009; 35(2): 122-143.

31. Fenton KA, Johnson AM, McManus S, Erens B. Measuring sexual behaviour:

methodological challenges in survey research. Sexually transmitted infections 2001; 77(2): 84-92. 


\begin{tabular}{|c|c|}
\hline Topic* & Response set \\
\hline \multicolumn{2}{|l|}{ Sexual behaviours and function (...during the past month) } \\
\hline How often did you think about sex? & \multirow{5}{*}{$\begin{array}{l}\text { 7-point scale: 'not at all' to 'more than once a day'. Men answering 2-3 } \\
\text { times a month or more were classified as experiencing or participating } \\
\text { frequently in that particular sexual behaviour or activity }\end{array}$} \\
\hline How many times have you had or attempted sexual intercourse (vaginal, anal or oral)? & \\
\hline How frequently did you engage in other sexual activities (kissing, petting or fondling)? & \\
\hline How often did you masturbate? & \\
\hline How frequently did you awaken with a full erection? & \\
\hline \multicolumn{2}{|l|}{ Sexual problems (...during the past month) } \\
\hline Are you able to get or keep an erection which would be good enough for sexual activity? & $\begin{array}{l}\text { 4-point scale: 'always able', 'usually able', 'sometimes able' or 'never } \\
\text { able'. Men answering never able were classified as having erectile } \\
\text { dysfunction (ED) }\end{array}$ \\
\hline When you had sexual stimulation how difficult was it for you to reach orgasm? & $\begin{array}{l}\text { 5-point scale: 'impossible' to 'not at all'. Men answering moderately } \\
\text { difficult to impossible were classified as having difficulty achieving orgasm }\end{array}$ \\
\hline Has your sexual desire/drive changed? & \multirow{4}{*}{$\begin{array}{l}\text { 5-point scale: 'increased a lot' to 'decreased a lot'. Men answering } \\
\text { decreased moderately or decreased a lot were classified as experiencing a } \\
\text { decline in that particular sexual behaviour or function over the preceding } \\
\text { year }\end{array}$} \\
\hline Has the overall frequency of you sexual activities changed? & \\
\hline Has your ability to have an erection changed? & \\
\hline Has the frequency of your waking erections changed? & \\
\hline \multicolumn{2}{|l|}{ Sexual health concerns (...during the past month) } \\
\hline Have you been worried or concerned by your level of sexual desire? & \multirow{5}{*}{$\begin{array}{l}\text { 5-point scale: 'not at all worried or concerned' to 'extremely worried or } \\
\text { concerned'. Men answering moderately, very or extremely worried or } \\
\text { concerned were classified as being concerned about that particular sexual } \\
\text { behaviour or activity }\end{array}$} \\
\hline Have you been worried or concerned by the frequency of your sexual activities? & \\
\hline Have you been worried or concerned by your ability to have an erection? & \\
\hline Have you been worried or concerned by the frequency of your waking erections? & \\
\hline Have you been worried or concerned by your orgasmic experience? & \\
\hline Partnership satisfaction (...during the past three months) & \\
\hline
\end{tabular}




\begin{tabular}{|c|c|}
\hline How often did you and your partner share the same sexual likes and dislikes? & 5-point scale: 'never' to 'always'. Men answering never or much less than \\
\hline How often did you feel emotionally close to your partner when you had sex? & $1 / 2$ the time were defined as not sharing same likes or emotional closeness \\
\hline How worried or concerned have you been about your overall sex life? & $\begin{array}{l}\text { 5-point scale: 'not at all worried' to 'extremely worried'. Men answering } \\
\text { moderately, very or extremely worried were classified as being concerned }\end{array}$ \\
\hline How satisfied have you been with your overall sex life? & $\begin{array}{l}\text { 5-point scale: 'very satisfied' to 'very dissatisfied'. Men answering } \\
\text { moderately dissatisfied or very dissatisfied were classified as dissatisfied }\end{array}$ \\
\hline
\end{tabular}


Table 2 | Characteristics of men who answered the ELSA sexual relationships and activities questionnaire: by PDE5i use/ED status. Values are weighted percentages ( $95 \%$ confidence intervals).

\begin{tabular}{|c|c|c|c|}
\hline Characteristic & No ED ( $n=1879)$ & PDE5i use $(n=191)$ & $\begin{array}{l}\text { Untreated ED } \\
\quad(n=542)\end{array}$ \\
\hline \multicolumn{4}{|l|}{ Age (years) } \\
\hline $50-59$ & $45.5(42.6-48.5)$ & $30.5(21.5-39.5)$ & $5.5(2.6-8.5)$ \\
\hline $60-69$ & $36.1(33.6-38.5)$ & $43.9(35.9-51.9)$ & $22.1(18.5-25.8)$ \\
\hline $70-79$ & $15.4(13.8-17.0)$ & $20.9(14.8-27.0)$ & $40.5(36.0-44.9)$ \\
\hline $80->90$ & $3.0(2.2-3.8)$ & $4.7(1.1-8.3)$ & $31.9(27.2-36.5)$ \\
\hline \multicolumn{4}{|l|}{ Current partner } \\
\hline Married or cohabiting & $75.1(72.6-77.6)$ & $73.0(64.9-81.0)$ & $70.1(65.5-74.7)$ \\
\hline No partner & $24.9(22.4-27.4)$ & $27.0(19.0-35.1)$ & $29.9(25.3-34.5)$ \\
\hline \multicolumn{4}{|l|}{ Age left education (years) } \\
\hline$\leq 14$ & $3.5(2.6-4.3)$ & $10.2(5.6-14.9)$ & $24.3(19.9-28.8)$ \\
\hline $15-18$ & $69.7(67.1-72.3)$ & $60.7(52.6-68.8)$ & $63.6(58.9-68.2)$ \\
\hline$\geq 19$ & $26.8(24.2-29.4)$ & $29.1(21.5-36.6)$ & $12.1(9.4-14.9)$ \\
\hline \multicolumn{4}{|l|}{ Self-rated general health } \\
\hline Fair or poor & $21.0(18.6-23.3)$ & $28.8(21.1-36.6)$ & $49.8(45.1-54.4)$ \\
\hline \multicolumn{4}{|c|}{ Self-reported chronic conditions } \\
\hline High blood pressure $^{a}$ & $35.2(32.5-37.8)$ & $48.9(40.5-57.3)$ & $56.5(51.8-61.1)$ \\
\hline Arthritis & $24.0(21.8-26.2)$ & $33.1(25.3-40.9)$ & $42.2(37.6-46.8)$ \\
\hline $\mathrm{CVD}^{\mathrm{b}}$ & $16.9(14.9-18.9)$ & $24.3(17.5-31.0)$ & $42.1(37.5-46.7)$ \\
\hline Diabetes $^{a}$ & $8.7(7.2-10.2)$ & $23.1(15.9-30.3)$ & $21.9(18.1-25.7)$ \\
\hline Asthma $^{\mathrm{a}}$ & $8.1(6.8-9.5)$ & $11.2(5.2-17.2)$ & $11.4(8.7-14.2)$ \\
\hline Depression $^{c}$ & $9.7(7.7-11.6)$ & $14.3(7.7-21.0)$ & $16.7(12.7-20.8)$ \\
\hline \multicolumn{4}{|l|}{ Smoking status } \\
\hline Current & $15.4(13.2-17.7)$ & $16.1(10.1-22.1)$ & $11.5(7.9-15.1)$ \\
\hline \multicolumn{4}{|c|}{ Frequency of alcohol consumption ${ }^{d}$} \\
\hline Never or rarely & $18.4(16.1-20.8)$ & $15.4(9.4-21.4)$ & $31.7(27.0-36.3)$ \\
\hline Regularly & $57.7(54.9-60.5)$ & $59.3(51.2-67.5)$ & $43.5(38.8-48.1)$ \\
\hline Very Frequently & $23.8(21.6-26.1)$ & $25.3(18.3-32.2)$ & $24.9(20.7-29.1)$ \\
\hline \multicolumn{4}{|c|}{${ }^{\mathrm{a} A}$ Also includes self-reported use of medications to control/prevent these chronic conditions } \\
\hline \multicolumn{4}{|c|}{${ }^{\mathrm{b}}$ Heart conditions and/or stroke } \\
\hline \multicolumn{4}{|c|}{${ }^{\mathrm{C}} \mathrm{CES}-\mathrm{D}$ (8-item) score of $\geq 4$} \\
\hline \multicolumn{4}{|c|}{$\begin{array}{l}\text { d Typical frequency of alcohol consumption over the past year (never or rarely = never to once or twice, } \\
\text { regularly = once every } 2 \text { months to twice a week, frequently = } 3 \text { days a week to almost every day) }\end{array}$} \\
\hline
\end{tabular}




\begin{tabular}{|c|c|c|c|c|c|}
\hline \multirow[b]{2}{*}{ Characteristic } & No ED & PDE5i use & Untreated ED & $\begin{array}{l}\text { PDE5i use vs. } \\
\text { no ED (reference) }\end{array}$ & $\begin{array}{l}\text { Untreated ED vs. } \\
\text { no ED (reference) }\end{array}$ \\
\hline & \multicolumn{3}{|c|}{$\%(95 \% \mathrm{Cl})$} & \multicolumn{2}{|c|}{ OR $(95 \% \mathrm{CI})^{a}$} \\
\hline \multicolumn{6}{|l|}{ Sexual function } \\
\hline Any sexual activity in last year & $88.2(86.5-89.9)$ & $97.2(94.3-100)$ & $32.5(28.3-36.8)$ & $6.45(2.15-19.4)^{*}$ & $0.18(0.13-0.24)^{*}$ \\
\hline Frequent sexual thoughts & $89.6(88.0-91.2)$ & $92.3(88.1-96.5)$ & $42.0(37.5-46.6)$ & $1.68(0.89-3.14)$ & $0.22(0.16-0.30)^{*}$ \\
\hline Frequent sexual intercourse $^{b}$ & $50.0(47.0-53.1)$ & $67.9(60.3-75.6)$ & $7.5(3.8-11.2)$ & $2.93(1.99-4.31)^{*}$ & $0.15(0.08-0.26)^{*}$ \\
\hline Frequent kissing, fondling or petting ${ }^{\mathrm{b}}$ & $63.8(60.9-66.8)$ & $78.6(72.2-85.0)$ & 42.5 (34.9-49.9) & $2.61(1.75-3.90)^{*}$ & $0.60(0.42-0.87)^{*}$ \\
\hline Frequent masturbation $^{\mathrm{b}}$ & $46.5(43.5-49.6)$ & $37.9(29.5-46.3)$ & $26.9(20.1-33.6)$ & $0.73(0.50-1.09)$ & $0.75(0.51-1.12)$ \\
\hline Frequent waking erections & $61.2(58.5-63.9)$ & $56.7(48.6-64.8)$ & $8.3(5.6-11.0)$ & $0.91(0.65-1.28)$ & $0.12(0.08-0.18)^{*}$ \\
\hline Difficulty achieving orgasm ${ }^{c}$ & $11.2(9.3-13.1)$ & $24.2(17.5-30.9)$ & $63.4(54.2-72.6)$ & $2.14(1.44-3.19)^{*}$ & $6.92(4.29-11.2)^{*}$ \\
\hline \multicolumn{6}{|l|}{ Compared with a year ago decreased... } \\
\hline Frequency of sexual activities ${ }^{b}$ & $35.2(32.3-38.2)$ & $36.9(28.8-45.0)$ & $53.9(46.3-61.6)$ & $1.05(0.72-1.53)$ & $2.00(1.40-2.87)^{*}$ \\
\hline Ability to have an erection & $20.7(18.5-23.0)$ & $37.5(29.4-45.6)$ & $45.2(40.6-49.9)$ & $2.19(1.49-3.23)^{*}$ & $2.03(1.55-2.66)^{*}$ \\
\hline Frequency of waking erections & $18.5(16.5-20.6)$ & $27.3(19.9-34.7)$ & $40.3(35.6-44.9)$ & $1.50(0.99-2.27)$ & $1.83(1.38-2.42)^{*}$ \\
\hline
\end{tabular}

${ }^{a}$ Logistic regression adjusted for age, self-rated general health (Excellent/Very Good/Good vs. Fair/Poor), frequency of alcohol consumption (Never/Rarely vs. Regularly or Very Frequently) and age left education ( $\leq 14$ years vs. $15-18$ years or $\geq 19$ years)

${ }^{b}$ Asked of those reporting any sexual activity in the past year $(n=2002)$

${ }^{\mathrm{c}}$ Asked of those reporting any sexual activity in the past month $(\mathrm{n}=1784)$

$* P<0.05$ 
Table 4 | Concerns about sexual activity/function and partnership factors among men: by PDE5i use/ED status. Values are weighted percentages or odds ratios ( $95 \%$ confidence intervals).

\begin{tabular}{|c|c|c|c|c|}
\hline No ED & PDE5i use & Untreated ED & $\begin{array}{l}\text { PDE5i use vs. } \\
\text { no ED (reference) }\end{array}$ & $\begin{array}{l}\text { Untreated ED vs. } \\
\text { no ED (reference) }\end{array}$ \\
\hline & $\%(95$ & & \multicolumn{2}{|c|}{ OR $(95 \% \mathrm{Cl})^{a}$} \\
\hline
\end{tabular}

Characteristic

$\%(95 \% \mathrm{Cl})$ OR $(95 \% \mathrm{Cl})^{a}$

Concerned about...

\begin{tabular}{|c|c|c|c|c|c|}
\hline Level of sexual desire & $12.0(10.0-14.0)$ & $27.9(20.5-35.3)$ & $17.6(14.2-21.0)$ & $2.96(1.92-4.56)^{*}$ & $2.29(1.56-3.37)^{*}$ \\
\hline Frequency of sexual activities ${ }^{b}$ & $11.8(9.9-13.8)$ & $21.9(14.4-29.4)$ & $25.1(18.6-31.6)$ & $2.08(1.24-3.47)^{*}$ & $2.84(1.82-4.43)^{*}$ \\
\hline Ability to have an erection & $8.9(7.4-10.5)$ & $40.6(32.4-48.9)$ & $22.2(18.4-26.0)$ & $6.87(4.58-10.3)^{*}$ & 2.73 (1.87-3.99)* \\
\hline Frequency of waking erections & $5.0(3.8-6.2)$ & $18.3(11.9-24.6)$ & $9.4(6.7-12.1)$ & $3.93(2.32-6.66)^{*}$ & $2.12(1.24-3.61)^{*}$ \\
\hline Orgasmic experience $^{c}$ & $8.1(6.3-9.9)$ & $24.4(17.4-31.4)$ & $35.6(26.4-44.9)$ & $2.99(1.96-4.57)^{*}$ & $5.12(3.08-8.53)^{*}$ \\
\hline Divergent sexual likes/dislikes to partner ${ }^{d}$ & $17.2(14.3-20.2)$ & $22.0(14.3-29.7)$ & $42.8(28.6-57.0)$ & $1.34(0.79-2.26)$ & $3.09(1.59-6.01)^{*}$ \\
\hline Did not feel emotionally close during sex ${ }^{d}$ & $6.3(4.3-8.3)$ & $6.1(2.3-9.9)$ & $6.5(0.2-12.8)$ & $0.96(0.45-2.06)$ & $1.16(0.35-3.86)$ \\
\hline Concerned about overall sex life & $16.2(14.1-18.3)$ & $29.2(21.8-36.6)$ & $19.4(15.9-23.0)$ & $2.14(1.43-3.20)^{*}$ & $1.64(1.16-2.30)^{*}$ \\
\hline Dissatisfied with overall sex life $^{d}$ & $18.0(15.2-20.7)$ & $29.9(22.1-37.7)$ & $48.1(33.9-62.2)$ & $1.84(1.20-2.82)^{*}$ & $4.33(2.29-8.18)^{*}$ \\
\hline
\end{tabular}

${ }^{a}$ Logistic regression adjusted for age, self-rated general health (Excellent/Very Good/Good vs. Fair/Poor), frequency of alcohol consumption (Never/Rarely vs. Regularly or Very Frequently) and age left education ( $\leq 14$ years vs. $15-18$ years or $\geq 19$ years)

${ }^{\mathrm{b}}$ Asked of those reporting any sexual activity in the past year $(\mathrm{n}=2002)$

CAsked of those reporting any sexual activity in the past month $(n=1784)$

${ }^{\mathrm{d}}$ Asked of those reporting any partnered sexual activity in the past 3 months $(n=1307)$

$* P<0.05$ 